\title{
APLIKASI ADMINISTRASI KELURAHAN DI DESA CILEUNGSI KIDUL UNTUK MENINGKATKAN PELAYANAN BAGI WARGA DAN APARAT KELURAHAN
}

\author{
Marlina $^{1}$, Dwipo Setyantoro ${ }^{2}$, Siti Aisyah ${ }^{3}$, Nur Ikmah ${ }^{4}$ \\ ${ }^{1}$ Jl. Diponegoro No.74 Jakarta Pusat, Telp.021-83430876 email: linabahar@ymail.com \\ 2,3 Jl. Diponegoro No.74 Jakarta Pusat, \\ ${ }^{4} J l$. Salemba Raya No.7/9 Jakarta Pusat
}

\begin{abstract}
Abstrak
Pelayanan administrasi kelurahan di desa cileungsi kidul masih berjalan secara manual yaitu pengelolaan data masih tercatat di dalam buku tidak secara komputerisasi, data tersebut berupa kartu keluarga, surat keterangan dsb. Berdasarkan masalah maka dibuatlah database pelayanan kelurahan dengan tujuan agar pihak aparat kelurahan dapat dengan mudah mengelola data secara komputerisasi dan tersimpan. Metodologi yang digunakan adalah pengembangan sistem dengan SDLC. Hasil dari pengembangan sistem ini berupa pemasukan data penduduk baru, perubahan data penduduk, penghapusan data penduduk dan pencarian data penduduk serta pembuatan laporan kependudukan yang tidak sedikit jumlahnya dan harus diserahkan ke tingkat kecamatan dan walikotamadya dalam waktu yang relatif singkat. Selama ini pemrosesan data tersebut dilakukan secara manual sehingga sering terjadinya penyimpangan data sedangkan pemrosesannya secara terkomputerisasi dapat terhindar dari segala resiko yang tidak diinginkan.
\end{abstract}

Kata Kunci : Pelayanan administrasi, Kelurahan Desa Cileungsi Kidul, Aplikasi Kelurahan

\begin{abstract}
Administrative services in the village of Cullinan Diamond village to the South still running manually, data management is still listed in the book are not computerized family data, maps, and so on. On the basis of the problem, make the database administrative services with the aim that the Administration can easily manipulate the data in the computerized and stored. The methodology used for the development of the SDLC. The outcome of the development of this system in the data entry form new residents, changes in demographic data, population data and demographic data search and reporting population that are not little and should be represented in the regional and municipal level within a relatively short period of time. During this time, the data processing is performed manually, so frequent violations while processing of computer data can be protected from any unwanted risks.
\end{abstract}

Key Word : administrative services, Cullinan village village, administrative applications

\section{PENDAHULUAN.}

Desa cileungsi kidul merupakan salah satu satu desa di kecamatan cileungsi kabupaten bogor dengan luas wilayah 622,25 ha, dengan curah hujan rata - rata $2,000 \mathrm{~mm} / \mathrm{tahun}$. Jumlah penduduk desa Cileungsi kidul sampai bulan Desember 2010 adalah 25,433 jiwa yang terdiri dari laki - laki 12.934 jiwa, perempuan 12.499 jiwa dengan jumlah kepala keluarga 7.601 KK dengan jumlah masyarakat miskin $650 \mathrm{kk}$ dengan prosentase $11,6 \%$ dari jumlah keluarga yang ada di desa cileungsi kidul.

Adapun batas - batas wilayah desa yaitu sebelah utara berbatasan dengan desa cileungsi, desa cipenjo dan desa limusnunggal, sebelah timur berbatasan dengan desa mekarsari, sebelah selatan berbatasan desa dayeuh, dan sebelah barat berbatasan dengan desa cileungsi dan kecamatan gunung putri bogor. Jumlah penduduk dan batasan wilayah desa yang begitu luas, maka dibutuhkan pendataan jumlah penduduk dan batasan wilayah oleh pemerintah sebagai contoh KTP (Kartu Tanda Penduduk). Selanjutnya dari data yang didapat, pihak kelurahan dapat memperoleh data tersebut menjadi arsip kependudukan dan berbentuk laporan yang akan dipertanggung jawabkan kepada tingkat kecamatan dan tingkat yang lebih tinggi.

Pemrosesan data tersebut pihak kelurahan memerlukan kerapian dan ketelitian serta kecepatan dalam pemrosesan data seperti halnya memasukkan data penduduk baru, perubahan data penduduk, penghapusan data penduduk dan pencarian data penduduk serta pembuatan laporan kependudukan yang tidak sedikit jumlahnya dan harus diserahkan ke tingkat kecamatan dan walikotamadya dalam waktu yang relatif singkat. Selama ini pemrosesan data tersebut dilakukan secara manual yang banyak memakan waktu dan sering terjadinya penyimpangan data. Apabila pemrosesannya dilakukan secara 
terkomputerisasi, maka dapat terhindar dari segala resiko yang tidak diinginkan sehingga tidak membahayakan data seluruh penduduk di Kelurahan tersebut, resiko yang dapat terjadi seperti halnya ketidakteraturan data, baik itu kerusakan, kerangkapan, kehilangan maupun kesalahan lainnya yang tidak diharapkan terjadi.

Tujuannya adalah membantu para pegawai kelurahan dalam pencarian data yang dapat dilakukan dengan relatif lebih cepat dan mudah serta meningkatkan pelayanan dalam bentuk pembuatan laporan kependudukan seperti surat-surat permohonan KTP, KK, Akte Kelahiran, Domisili, Asal Usul, domisili Usaha dan dalam bentuk yang lainya karena mengacu pada $\mathrm{E}$ - Kelurahan.

\section{METODE PENELITIAN}

Metode pendekatan yang dilakukan adalah memberikan rancang bangun database administrasi kelurahan, rancang jaringan sistem, dan pelatihan persoalan dengan menerapkan model-model manajemen pengelolaan data, dan teknologi informasi.

Solusi yang ditawarkan meliputi (a) Manajemen pengelolaan data kelurahaan, (b) Model pengembangan sistem dengan melakukan rancang bangun aplikasi aplikasi pelayanan administrasi cileungsi kidul, (c) Model instalasi jaringan secara local host agar aplikasi dapatdigunakan oleh beberapa computer, (d) Model pelatihan teknologi ekelurahaan, agar aplikasi dan jaringan yang telah dibangun dapat diuji coba oleh aparat dan beberapa warga yang diwakili oleh aparat dan karang taruna.

\section{HASIL DAN PEMBAHASAN}

Setelah melihat permasalahan yang ada, maka penulis akan membuat suatu sistem informasi yang mempunyai fungsionalis antara lain (a) proses penginputan data induk, data penduduk, data surat keterangan (b) proses pengeditan data berupa memasukkan data master, data penduduk dan data surat keterangan, proses ini dilakukan pada kolom tampilan dan dapat langsung di edit pada setiap kategori data yang ada. (c) proses penyediaan informasi berupa tampilan input data induk, tampilan input data penduduk, tampilan input data surat keterangan, tampilan bantuan, tampilan pencarian, mencetak laporan berdasarkan setiap kategori data, mengedit, mengupdate dan menghapus untuk setiap kategori data.

Sedangkan spesifikasi pengguna diantaranya (a) Admin, bertugas melakukan edit data warga desa cileungsi kidul, input, edit, update dan hapus data warga desa cileungsi kidul, mengontrol sistem (b) user, bertugas melihat informasi yang terdapat di sistem, melakukan print out sendiri, mencari data yang dibutuhkan. Secara fisik sistem ini dijelaskan sebagai berikut :

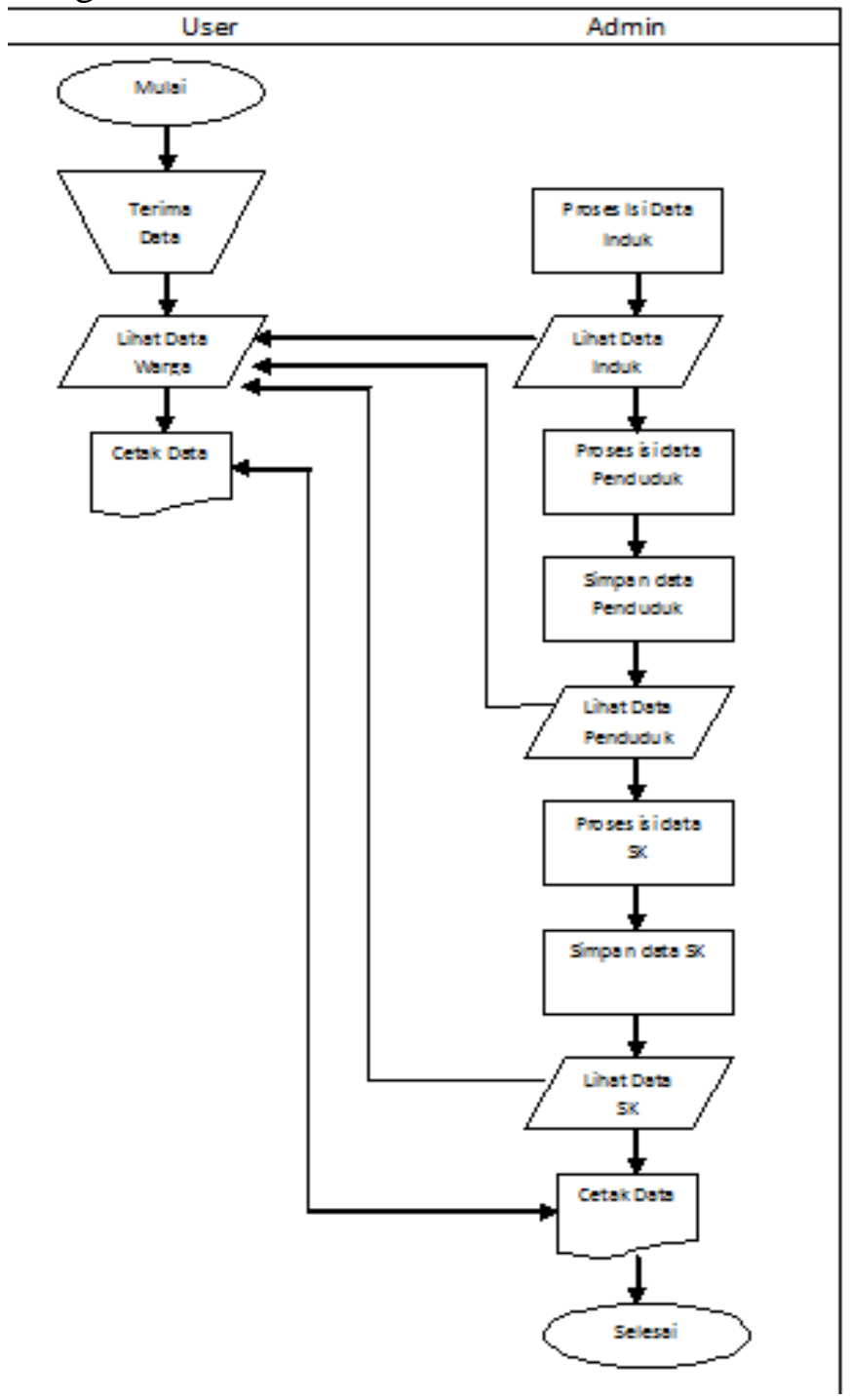

Ada beberapa komputer yang akan dijadikan client dan satu komputer menjadi server yang ditugaskan dalam melakukan pengolahan data dan mengelola semua sistem. Beberapa komputer yang menjadi client hanya bisa melakukan pencetakan data, sedangkan server yang melakukan menginput data, mengedit, dan mengupdate data. Adapun solusi yang ditawarkan dalam sistem ini adalah : 
Melakukan observasi awal pada kelurahan cileungsi kidul untuk mengetahui apa saja yang diperlukan untuk kelurahan tersebut. Identifikasi persoalan dan perumusan masalah yang terdapat di dalam pengelolaan manajemen data adalah rencana pengembangan sistem aplikasi administrasi kelurahan untuk meningkatkan pelayanan kelurahan. Hasil identifikasi tersebut maka dilakukan analisa masalah yang terjadi di kelurahan, kemudian pengumpulan data data yang dibutuhkan untuk pengembangan sistem administrasi pelayanan, dan melakukan perancangan sistem administrasi pelayanan dengan menentukan data-data yang terhubung terhadap database, hasil relasi data tersebut dapat dilihat oleh beberapa komputer dengan media server melalui instalasi jaringan secara local host. Hasil rancangan dan instalasi jaringan, dapat diuji coba kepada karyawan kelurahan dan beberapa warga diwakili oleh karang taruna. Setelah uji coba sistem, maka dapat dilakukan pelatihan agar user (pengguna) dapat melihat kebutuhan yang diinginkan telah sesuai dengan kebutuhan. Hasil pelatihan tersebut, maka sistem dapat dipergunakan untuk meningkatkan pelayanan warga desa cileungsi kidul.

Instalasi jaringan secara local host antara 1 server dan 2 client server, berikut ini kondisi letak komputer yang terdapat di kelurahan Cileungsi kidul (gambar 1). Komputer yang dibutuhkan adalah komputer yang memiliki memori $512 \mathrm{~KB}$, processor pentium 4, harddisk 40 gegabyte, monitor LG. Jaringan W-LAN yang kita rancang untuk dibangun memerlukan beberapa persiapan seperti perangkat keras dan perangkat lunak serta fasilitas yang memadai agar jaringan ini dapat bekerja secara maksimal. Yang pertama kita butuhkan yaitu 2 buah komputer sebagai klien, Satu buah komputer server/admin kita letakan diruangan sekretaris desa karena tempatnya luas dan tidak ramai dengan aktifitas perusahaan, Wi-Fi untuk koneksi Hotspot berupa card Wireless LAN/Wi-Fi yang dipasang di notebook/klien dapat berupa Compact Flash,Embedded Card dan USB WLAN, Router sebagai penghubung dengan access point.
Komputer klien yang terletak di ruang tata usaha/sekretariat langsung terhubung dengan router yang sudah mempunyai jaringan $\mathrm{W}$ LAN yang dapat ditarik gelombang sinyalnya dengan cara seperti kita ingin melakukan koneksi internet. Setiap menu satu dengan yang lain saling berhubungan sesuai dengan penggunaan.

\section{KESIMPULAN}

Setelah melakukan penelitian, pengamatan, perancangan, implementasi dan uji coba sistem, maka penulis menyimpulkan bahwa sistem administrasi kelurahan ini sudah dapat digunakan sesuai dengan kebutuhan dari pihak kelurahan. Sistem administrasi kelurahan yang dibangun adalah menu data induk, menu data penduduk, menu surat keterangan, menu bantuan, menu pencarian penduduk. Sedangkan instalasi jaringan yang telah di instalasi dapat membantu pihak kelurahan untuk mengelola data sesuai dengan kebutuhannya masing-masing, seperti pihak administrasi umum \& sarana prasarana serta pihakadministrasi keuangan dapat saling melihat data melalui data yang telah di sharing oleh server, sedangkan pihak sekdes sebagai admin dan sebagai server.

\section{DAFTAR PUSTAKA}

[1] Amsya Zulkifli, 2000 "Manajemen Sistem Informasi “, Gramedia Pustaka Utama

[2] Hariyanto, Bambang, 2004 "Sistem Manajemen Basis Data", Informatika Bandung

[3] Betha, Sidik, 2004 "Pemrograman Web dengan PHP, Informatika Bandung

[4] Jogiyanto H.M, 1996 "Analisis dan Desain", Andi Offset Yogya

[5] Kadir, Abdul, 2003 "Pengenalan Sistem Informasi", Andi Offset Yogya

[6] Nugroho, Bunafit, 2008 "Latihan Membuat Aplikasi Web PHP dan MySql dengan

[7] Dreamweaver MX", Gaya Media Yogya

[8] Manual PHP, http://www.php.net, 2011

[9] Manual MYSQL, http://www.mysql.com, 2011

[10] Tutorial Lengkap, 
[11] Syafrizal Melwin, 2005 "Pengantar Jaringan Komputer Edisi 1, Penerbit Andi Yogya
[12] http://rachmad29.blogspot.com/2008/1 2/tipe-tipe-router-ospf.html

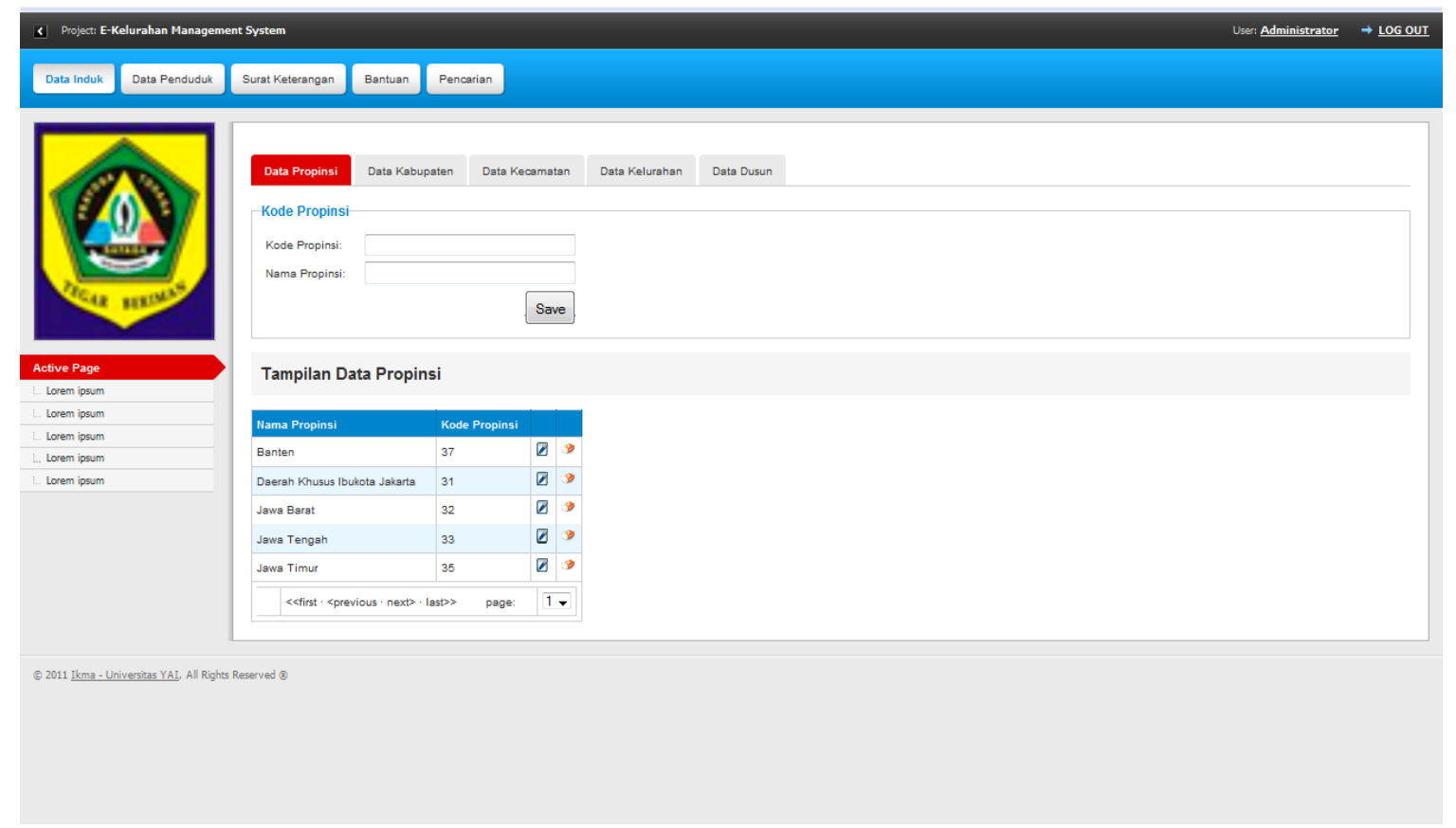

Gambar 1 : Data Induk

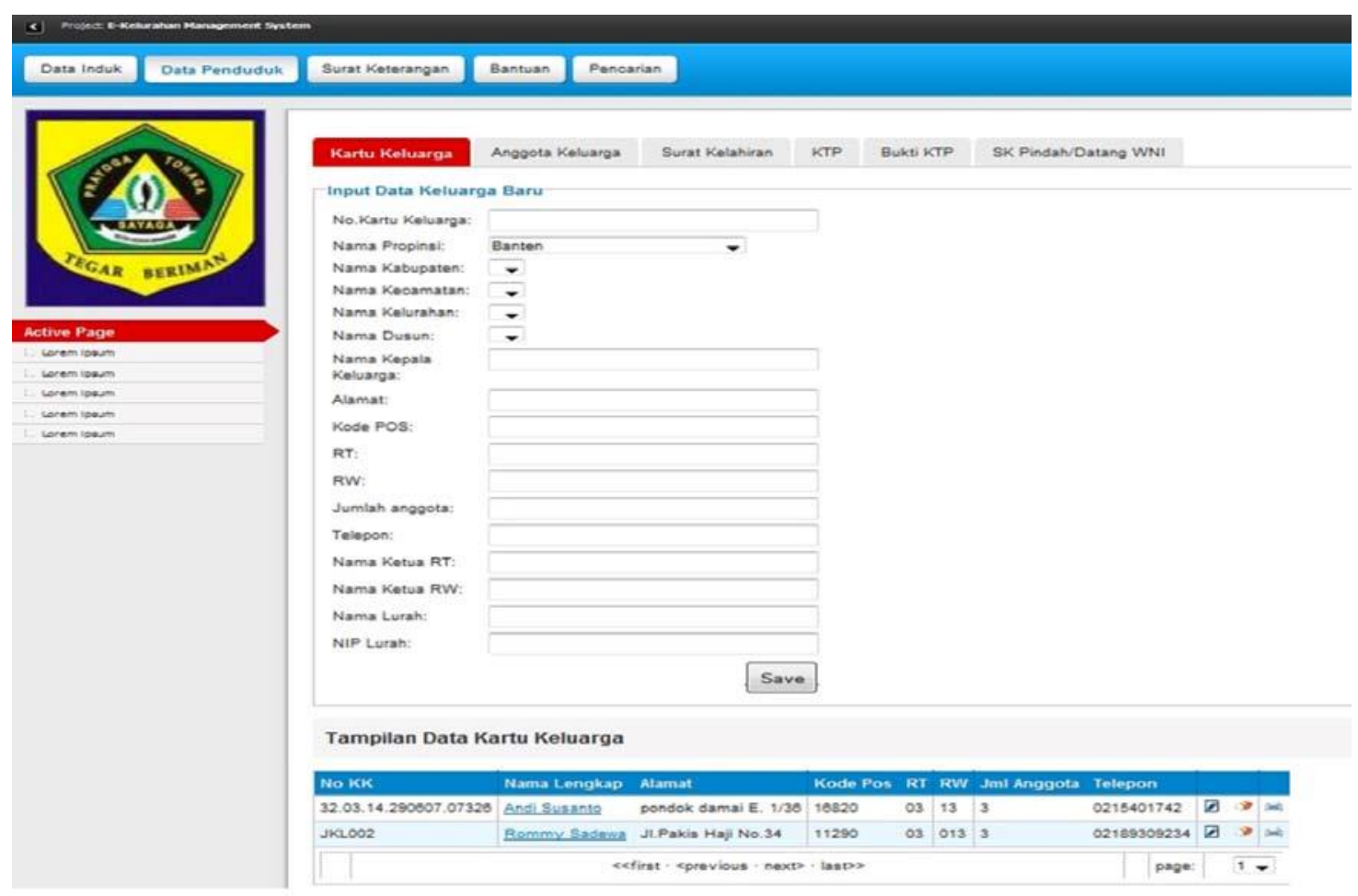

Gambar 2 : Data Penduduk 


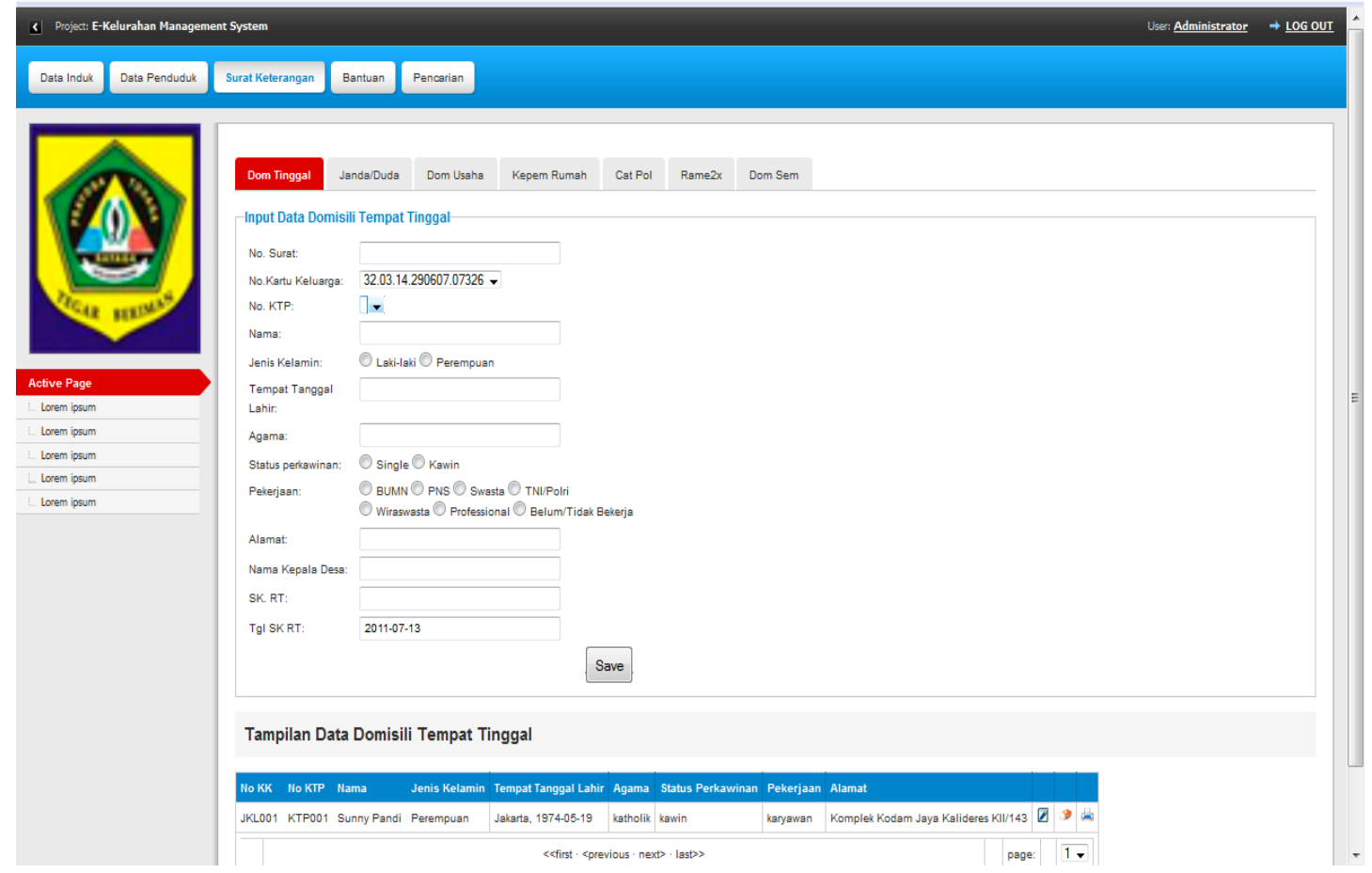

Gambar 3: Surat Keterangan

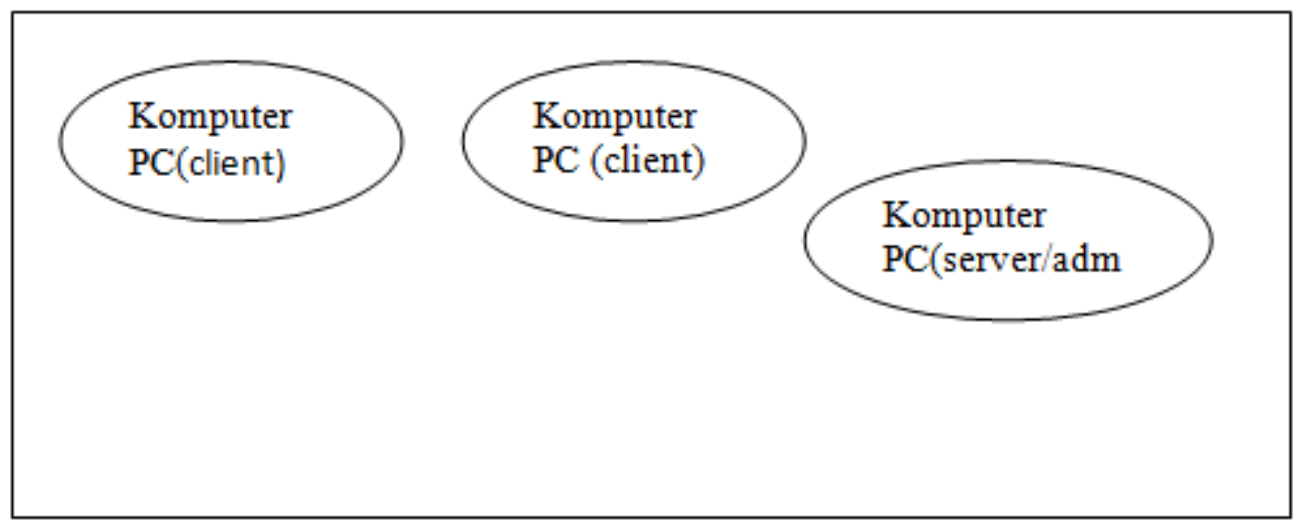

Gambar 4: Letak Komputer sebelum dibangun

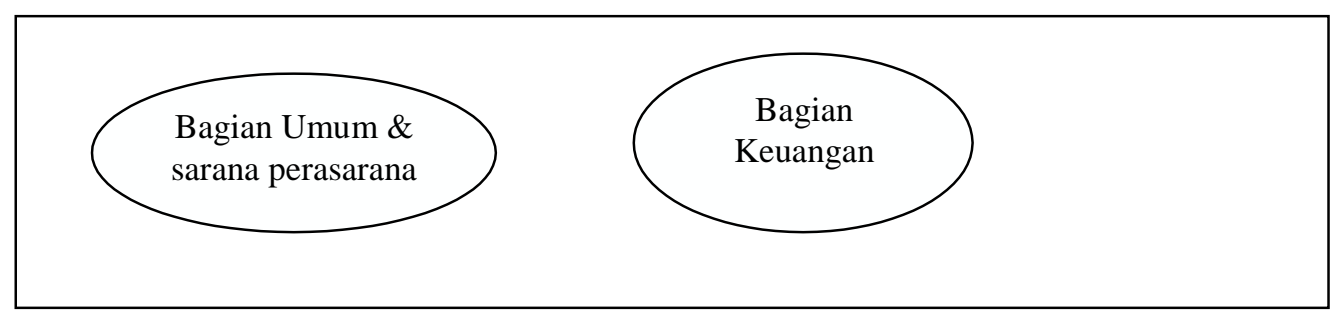

Gambar 5 : Letak komputer klien di ruang tata usaha/secretariat 


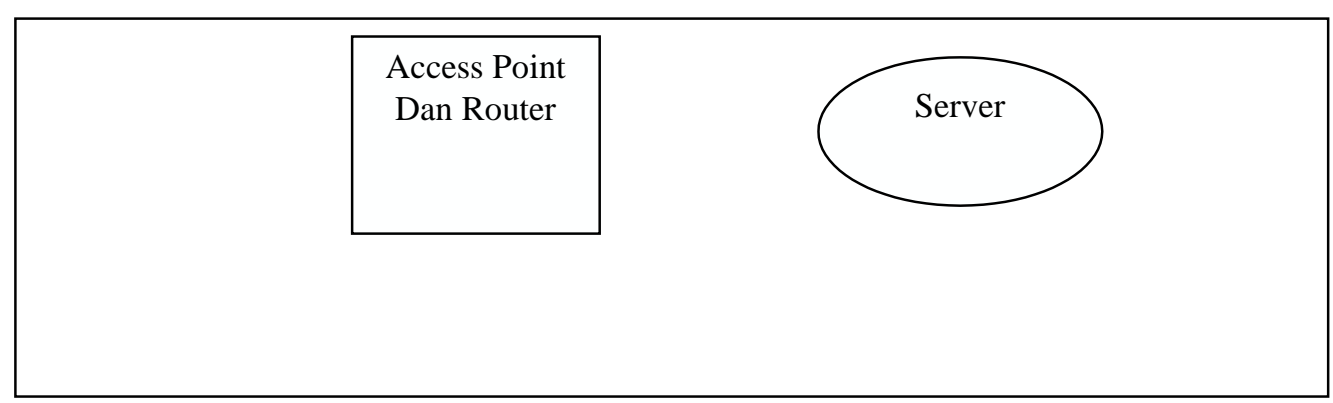

Gambar 6 : Letak server/admin di ruang sekretaris desa 
